\title{
Journal of Paediatrics and Child Health
}

\section{Placental histopathology in preterm fetal growth restriction}

\begin{tabular}{|c|c|}
\hline Journal: & Journal of Paediatrics and Child Health \\
\hline Manuscript ID & JPC-2018-0525.R1 \\
\hline Manuscript Type: & Original Article \\
\hline Keywords: & Neonatology \\
\hline Abstract: & $\begin{array}{l}\text { Aims: Approximately } 6-9 \% \text { pregnancies are affected by fetal growth } \\
\text { restriction (FGR). Placental alterations related to utero-placental } \\
\text { insufficiency in fetal growth restriction (FGR) may induce placental vascular } \\
\text { remodeling to the detriment of the fetus. The objective of this study was to } \\
\text { study histopathological features of placentae in a cohort of preterm growth } \\
\text { restricted infants in comparison to a cohort of preterm appropriately grown } \\
\text { infants. } \\
\text { Methods: In a cohort of } 40 \text { preterm infants' } 28-32 \text { weeks' gestation, } \\
\text { placental histopathology was evaluated by a histopathologist, masked to } \\
\text { the identity of the grouping. Twenty infants had FGR while } 20 \text { were } \\
\text { appropriate for gestational age (AGA). Predefined histopathological } \\
\text { characteristics were assessed based on the Amsterdam Placental Workshop } \\
\text { Group Consensus Statement. } \\
\text { Results: The GA and birthweight of the FGR and AGA cohorts were } \\
29.8 \pm 1.3 \text { vs } 30 \pm 0.9 \text { weeks, p=0.78 and } 923 \pm 168 \text { vs } 1403 \pm 237 g,<0.001 \text {, } \\
\text { respectively. Maternal vascular malperfusion, accelerated villous } \\
\text { maturation and fetal vascular malperfusion were features which were } \\
\text { significantly more common in FGR placentae. } \\
\text { Conclusions: Based on the results of the present study, specific placental } \\
\text { histopathological changes may be present in FGR placentae which may } \\
\text { reflect the effects of utero-placental insufficiency. } \\
\text { Key words: fetal growth restriction; histopathology; preterm; placenta; } \\
\text { vascular malperfusion }\end{array}$ \\
\hline
\end{tabular}

\section{SCHOLARONE ${ }^{\text {m }}$ \\ Manuscripts}




\begin{abstract}
Aims: Approximately 6-9\% pregnancies are affected by fetal growth restriction (FGR). Placental alterations related to utero-placental insufficiency in fetal growth restriction (FGR) may induce placental vascular remodeling to the detriment of the fetus. The objective of this study was to study histopathological features of placentae in a cohort of preterm growth restricted infants in comparison to a cohort of preterm appropriately grown infants.

Methods: In a cohort of 40 preterm infants' 28-32 weeks' gestation, placental histopathology was evaluated by a histopathologist, masked to the identity of the grouping. Twenty infants had FGR while 20 were appropriate for gestational age (AGA). Predefined histopathological characteristics were assessed based on the Amsterdam Placental Workshop Group Consensus Statement.

Results: The GA and birthweight of the FGR and AGA cohorts were $29.8 \pm 1.3$ vs $30 \pm 0.9$ weeks, $\mathrm{p}=0.78$ and $923 \pm 168$ vs $1403 \pm 237 \mathrm{~g},<0.001$, respectively. Maternal vascular malperfusion, accelerated villous maturation and fetal vascular malperfusion were features which were significantly more common in FGR placentae.

Conclusions: Based on the results of the present study, specific placental histopathological changes may be present in FGR placentae which may reflect the effects of utero-placental insufficiency.
\end{abstract}

Key words: fetal growth restriction; histopathology; preterm; placenta; vascular malperfusion 


\section{What is already known on this topic}

- Approximately 6-9\% pregnancies worldwide are affected by growth restriction

- Combined with prematurity, growth restriction worsens the outlook by increasing mortality and morbidity

- Utero-placental insufficiency is considered the common underlying aetiology

\section{What this paper adds}

- Identifies key placental histopathological characteristics in very preterm infants with FGR

- Studies placental pathology focussed on maternal/fetal malperfusion indices

- Classifies placental pathology according to the most recent consensus statement 


\section{Introduction}

Fetal growth restriction (FGR) affects about 6-9\% pregnancies worldwide, and a combination of prematurity and FGR increases the perinatal mortality or morbidity by 10-20 fold, compared to appropriately-grown preterm infants (1). It is the second highest cause of perinatal death and the commonest cause of stillbirth in the infant $(2,3)$. Fetal programming remains a well-established concept in epidemiological medicine with implications for fetal, pediatric and adult diseases. Abnormalities of the placenta, with reduced feto-placental blood flow accompanying utero-placental insufficiency (UPI), are a major cause of FGR (4-6). Previous data noted that in early FGR, the placental pathology is characterized by features of hypoxia and reperfusion damage caused by vascular remodelling and/or obstruction of spiral arteries $(7,8)$. Recent information also noted that pregnancies complicated by maternal vascular malperfusion had a 4.5 times higher risk of developing preeclampsia or delivering a FGR infant compared with those without this pathology (9). Importantly, in low-risk pregnancies, maternal vascular malperfusion accounts for approximately $25 \%$ of adverse pregnancy outcomes (such as FGR in the infant or preeclampsia) (9). Common adaptive mechanisms with advancing gestation in healthy pregnancies include a drop in placental vascular resistance and the establishment of a high flow circuit to optimise nutrient and oxygen delivery. This is achieved through vascular adaptations such as angiogenesis and vasodilatation $(4,10)$. In severe cases of FGR, these adaptive mechanism fail resulting in a persistently high placental vascular resistance.

Information from placental histopathology and biomarkers is key to a better understanding of perinatal disease pathophysiology. The physiologic consequences of the altered placental architecture may underlie persistent cardiovascular alterations noted in the newborn and pediatric age groups. This includes a lower elastin content in the extracellular matrix of fetal conductance arteries (due to feto-maternal blood flow abnormalities); elastin is the key determinant of elastic properties (11-15). Recent studies in preterm FGR lambs and human infants noted increased arterial stiffness in the early neonatal period $(16,17)$ which persist into childhood (18). Early identification may identify premature infants at high risk for long term cardiovascular compromise, and allow early intervention and/or increased monitoring.

The objectives of this study were to identify key placental histopathological characteristics in very preterm infants with FGR, compared to an appropriate for gestational 
age (AGA) cohort, with emphasis on maternal/fetal malperfusion indices. In this preliminary study, we hypothesize that in infants with FGR, the effects of UPI may be reflected in placental histopathological changes.

\section{Methods}

The study was approved by the Institution Health Research Ethics Board and informed parental consent was obtained. Twenty very preterm infants (28 to 32 completed weeks of gestation) with birthweight $<10^{\text {th }}$ percentile were compared with 20 preterm AGA infants of the same GA range. GA was determined by fetal dating ultrasound (19). Our selected GA range reflects the majority of moderate to severe early-onset FGR cases. Infants with possible asphyxia ( 5 minute Apgar score $<5$ ), congenital malformations/heart disease or chromosomal abnormalities, or infants of diabetic mothers were excluded. Archived slides for placental histopathology were examined by a single perinatal pathologist, masked to cohort identity and the clinical outcomes. Predefined histopathological characteristics were assessed based on the Amsterdam Placental Workshop Group Consensus Statement (20). At least three sections of the placental plate, two sections of the umbilical cord and a roll of the extraplacental membranes were examined. Features examined reflected maternal/fetal malperfusion (Table 1). The infants were part of an echocardiographic study for which assessments were made in the second week of life. In that setting, non-invasive blood pressure (BP) measurements were obtained using an appropriate-sized cuff on the right arm with the infant in a quiet state and positioned supine (model Intelli Vue MX 800; Philips, Boeblingen, Germany). The average values of 2 readings were recorded. Infants were prospectively followed to ascertain clinical respiratory morbidity.

\section{Statistics}

Continuous variables were compared using student's t-test and categorical variables were compared using Chi-square or Fisher's exact tests. All analyses were performed using Stata software version 13.0. Significance was set at two-tailed $\mathrm{p}<0.05$.

\section{Results}

The GA at birth amongst the two groups was comparable, but the birthweight was significantly lower in the FGR infants. Twelve of 20 FGR infants weighed $<3^{\text {rd }}$ centile. Table 
2 summarizes the salient demographic and placental characteristics of the study population. Amongst maternal demographics, cigarette smoking during pregnancy and body mass index data was available for only part of the cohort. Amongst FGR group, cigarette smoking was prevalent in 4 (of 17 mothers) compared to 1 (of 12 mothers) in the AGA cohort. Mean body mass index in the FGR cohort was 27.5 \pm 5.3 (16 mothers) compared to $25.9 \pm 4.1$ (10 mothers). Blood pressure was significantly higher in FGR infants; no infant was on inotropic support before or at the time of assessment. There were two sets of twins in each cohort; all dichorionic diamniotic. The number of FGR infants with placental changes secondary to maternal vascular malperfusion (such as placental infarcts, distal villous hypoplasia, accelerated villous maturation and decidual arteriopathy, placental ischemia, Figure 1a) and changes secondary to segmental fetal vascular malperfusion (such as fetal vessel thrombosis, avascular villi and stem vessel obliteration, Figure 1b) was significantly greater than AGA controls (Table 2). The placentas of three FGR infants showed chronic intervillositis (Figure 1c) and another three contained microscopic chorangiomas (Figure 1d) (Table 2). The fetoplacental weight ratio was 3.88 \pm 2.3 and $4.9 \pm 1.2$ in FGR and AGA infants respectively, $p=0.08$. The total duration of respiratory support and the number of infants with bronchopulmonary dysplasia was significantly higher in the FGR cohort. Four FGR infants (no AGA infant) were discharged with home oxygen.

\section{Discussion}

In this cohort of preterm infants we noted significant differences in placental histopathology in the FGR infants compared to AGA infants. Features of maternal and fetal malperfusion were significantly more common in the FGR infants. FGR infants had significantly higher blood pressure and inferior respiratory outcome profiles. This study thus contributes to our understanding of the pathology of the placenta, the scientific bases of the materno-fetoplacental triad, and the ever expanding clinical significance of the defined lesions.

Recent findings of increase placental vascular resistance in ex-vivo models complement what is seen on histopathology (21). Additionally, the persistence of increased resistance in systemic vessels in the early newborn, pediatric and adolescent age groups, supports the fetal programming theory, and placental pathology provides earliest clues to fetal origin of adult diseases $(17,18)$. Our study utilised the Amsterdam Placental Workshop Group Consensus Statement classification for pre-defined definitions and compared FGR 
placentas with gestation matched AGA placentas. Consistency in definition adds value to the placental examination, especially in those with adverse outcomes such as still birth or FGR.

The classic placental findings in FGR pregnancies may be seen on gross inspection (small size and lower weight) as well as on microscopic histopathology. Previous data has noted histopathology lesions to be related to reduced vascular supply of nutrients and oxygen due to maternal vascular malformation (e.g. infarction, villous hypoplasia and increased syncytial knotting) (22). Other findings include multiple thrombotic occlusions in fetal vessels (20) and chronic intervillositis $(20,23)$. In the sheep model of chronic fetal hypoxia, UPI leads to similar histologic findings of vascular remodelling with small lumens and thick walls (24). We noted significant differences between the two groups for maternal and fetal vascular malperfusion indices which might explain the dynamic impairments. In a recent study of flow dynamics on human term FGR placentas compared with AGA placentas, investigators demonstrated that the former had significantly higher resistance, endothelial dysfunction and reduced flow-mediated vasodilatation. The latter is likely caused by a combination of architectural vessel malformation and alterations in placental capillary angiogenesis (25). While UPI is likely the central event, the pathophysiological processes are multiple. The in-utero disruption in the synthesis and deposition of elastin and its replacement with collagen (100 times greater stiffness than elastin) in fetal life play an important role (11). The other critical mechanism is hypoxia induced oxidative stress. Attempts to improve placental function and fetal/neonatal outcomes by administration of drugs like melatonin and sildenafil (26-28) has guided the search for tangible histopathological markers. These may provide early indications and potentially guide the medical management principles with the ultimate objective of minimizing (or preventing) FGR. Melatonin treatment attenuated the thickness of the arteriolar wall and reduced oxidative and inflammatory markers in chronically hypoxic rats. Our group recently showed that in FGR sheep, umbilicoplacental insufficiency is associated with FGR-produced vascular changes in the white matter and subventricular zone of FGR newborn brains (27). Maternal melatonin prevented disruption of the blood brain barrier by protecting perivascular cells essential for the maintenance of vascular homeostasis and stability. Sildenafil is a vasodilator and its administration during pregnancy has been noted to improve placental blood flow.

Effects of these interventions on the above mentioned histopathological characteristics remains to be studied. While no one histopathology lesion could be considered pathognomonic, such changes are found more frequently in placentas where pregnancy was complicated by FGR. Given utero-placental insufficiency is the main underlying factor of 
FGR, maternal vascular pathology in the decidual vessels underlies a significant proportion FGR placentas. The inadequate trophoblastic invasion and the persistence of smooth muscle in the vessel walls may result in changes like atherosis or fibrinoid necrosis of vessels. Such architectural changes in placental vessel walls combined with endothelial dysregulation in FGR is possibly an important cause of placental flow dysregulation. Close histopathology examination of placentae in pregnancies which are complicated by FGR using standard classification and terminology will facilitate further large scale studies.

Our data noted a significantly higher incidence of BPD in the FGR cohort, compared to the GA and gender matched AGA infants. Information about respiratory morbidity from the early 70 s and 80 s suggested otherwise. Gluck et. al. suggested that the abnormalities of pregnancy, including maternal, fetal, and placental conditions, influence the maturation of the fetal lung (29). Certain conditions such as maternal hypertension may accelerate lecithin sphingomyelin ratio maturation. Procianoy et al. studied 19 small for GA infants' $\leq 32$ weeks GA and compared with an equal number of AGA infants. The incidences of hyaline membrane disease (HMD) was noted to be significantly less in the small for GA cohort (74\% vs $5 \%$ ) (30). The authors postulated that a stressful environment in utero may enhance maturation and prevent HMD.

Recent data however, has focussed on chronic lung disease (CLD) as a more tangible outcome (rather than HMD), and overwhelmingly supports the role of FGR in its pathophysiology. A recent study in infants born less than 28 weeks GA noted that at 27 weeks GA, 25\% of infants born without FGR developed CLD compared to $60 \%$ of infants with moderate FGR $\left(<10^{\text {th }}\right.$ centile for birthweight $)$ and $90 \%$ with severe FGR $\left(<3^{\text {rd }}\right.$ centile $)$ (31). Importantly, FGR was the only maternal or antenatal characteristic that was highly predictive of CLD. In an observational study on infants $<32$ weeks GA, FGR infants had a significantly higher risk of developing CLD (odds ratio: 1.87, 95\% confidence interval [CI]: 1.4-2.5) (32). While CLD pathophysiology is multifactorial, investigators have proposed a role for vascular changes as contributory to CLD pathophysiology $(33,34)$. A recent prospective study on preterm FGR infants (28-32 weeks GA) noted significantly thicker and stiffer pulmonary arterial vasculature compared to GA, gender and age matched AGA control infants as well as a significantly higher prevalence of CLD in the FGR cohort (34). This human data and other experimental data, indicates impaired vasculogenesis as a contributory factor in the higher prevalence of CLD in preterm FGR infants $(35,36)$. Persistent effects of FGR on lung structure and function (affecting both alveolar parenchymal and vascular 
components) indicates that reduced fetal growth may be a marker of abnormal intrauterine lung development. This clinically reflects in a greater prevalence of respiratory morbidities.

Strengths of our study include comparison of FGR with an AGA cohort and the assessment of placental histopathology by an expert perinatal pathologist, masked to the outcomes and grouping of the cohort. The evaluations were done using standard classifications and terminology. Whether placental architectural changes contribute to postnatal respiratory pathology by way of influencing angiogenesis needs prospective analysis. The findings are limited by being a single centre study and small numbers. Maternal demographic data was not available for the complete cohort. In summary, histopathological changes indicative of maternal and fetal malperfusion are significantly more likely in the placentas of preterm FGR infants. Whether placental findings could be the earliest pointers towards the effects of UPI on the placental vascular extracellular matrix, remains to be studied. This assumes significance, given the vascular remodelling, increased stiffness and reduced compliance persist in the neonatal and pediatric age groups.

\section{Acknowledgements}

Supported by an ANZ Trustees/Equity Trustees Medical Research \& Technology in Victoria Grant, a National Health and Medical Research Council and National Heart Foundation of Australia Fellowship, an Australian Research Council Future Fellowship, a Rebecca L. Cooper Medical Research Foundation Fellowship and the Victorian Government's Operational Infrastructure Support Program.

Conflicts of interest: Authors declare no conflicts of interest 


\section{References}

1. Rosenberg A. The IUGR newborn. Semin Perinatol. 2008; 32:219-24.

2. Yanney M \& Marlow N. Paediatric consequences of fetal growth restriction. Semin Fetal Neonatal Med 2004; 9: 411-418.

3. Figueroa-Diesel H, Hernandez-Andrade E, Acosta-Rojas R, Cabero L, Gratacos E. Doppler changes in the main fetal brain arteries at different stages of hemodynamic adaptation in severe intrauterine growth restriction. Ultrasound Obstet Gynecol 2007; 30: 297-302.

4. Chaddha V, Viero S, Huppertz B, Kingdom J. Developmental biology of the placenta and the origins of placental insufficiency. Semin Fetal Neonatal Med 2004; 9: 357-369.

5. Sibley CP, Turner MA, Cetin I, Ayuk P, Boyd CA, D’Souza SW, et al. Placental phenotypes of intrauterine growth. Pediatr Res 2005; 58: 827-832.

6. Kiserud T, Kessler J, Ebbing C, Rasmussen S. Ductus venosus shunting in growth-restricted fetuses and the effect of umbilical circulatory compromise. Ultrasound Obstet Gynecol 2006; 28: 143-149.

7. Brosens I, Pijnenborg R, Vercruysse L, Romero R. The "Great Obstetrical Syndromes" are associated with disorders of deep placentation. Am J Obstet Gynecol 2011; 204:193e201.

8. Kovo M, Schreiber L, Bar J. Placental vascular pathology as a mechanism of disease in pregnancy complications. Thromb Res 2013; 131: S18e21.

9. Wright, E, Audette MC, Ye XY, Keating S, Hoffman B, Lye SJ et al. Maternal Vascular Malperfusion and Adverse Perinatal Outcomes in Low-Risk Nulliparous Women. Obstet Gynecol. 2017; 130: 1112-1120.

10. Sala C, Campise M, Ambroso G, Motta T, Zanchetti A, Morganti A. Atrial natriuretic peptide and hemodynamic changes during normal human pregnancy. Hypertension 1995; 25: 631-636.

11. Martyn CN, Greenwald SE. Impaired synthesis of elastin in walls of aorta and large conduit arteries during early development as an initiating event in pathogenesis of systemic hypertension. Lancet 1997; 350:953-55. 
12. Cheung YF, Taylor MJ, Fisk NM, Tsoi NS. Fetal origins of reduced arterial distensibility in the donor twin in twin-twin transfusion syndrome. Lancet 2000; 355:1157-58.

13. Dobrin PB. Mechanical properties of arteries. Physiol Rev 1978; 58:397-460.

14. Lurbe E, Torro MI, Carvajal E, Alvarez V, Redón J. Birth weight impacts on wave reflections in children and adolescents. Hypertension 2003; 41:646-50.

15. Fouron JC, Teyssier G, Shalaby L, Lessard M, van Doesburg NH. Fetal central blood flow alterations in human fetuses with umbilical artery reverse diastolic flow. Am J Perinatol 1993; 10: 197-207.

16. Polglase GR, Allison BJ, Coia E, Li A, Jenkin G, Malhotra A, et al. Altered cardiovascular function at birth in growth-restricted preterm lambs. Pediatr Res. 2016; 80:538-46.

17. Sehgal A, Allison BJ, Gwini SM, Menahem S, Miller SL, Polglase GR. Vascular ageing and cardiac maladaptation in growth restricted preterm infants. J Perinatol; 2018; 38:92-97.

18. Crispi F, Figueras F, Cruz-Lemini M, Bartrons J, Bijnens B, Gratacos E. Cardiovascular programming in children born small for gestational age and relationship with prenatal signs of severity. Am J Obstet Gynecol 2012; 207:121.e1-9.

19. Fenton TR, Kim JH. A systematic review and meta-analysis to revise the Fenton growth chart for preterm infants. BMC Pediatr. 2013; 13: 59.

20. Khong TY, Mooney EE, Ariel I, Balmus NC, Boyd TK, Brundler MA, et al. Sampling and Definitions of Placental Lesions Amsterdam Placental Workshop Group Consensus Statement. Arch Pathol Lab Med. 2016; 140:698-713.

21. Jones S, Bischof H, Lang I, Desoye G, Greenwood SL, Johnstone ED, et al. Dysregulated flow-mediated vasodilatation in the human placenta in fetal growth restriction. J Physiol. 2015; 593:3077-92.

22. Veerbeek JH, Nikkels PG, Torrance HL, Gravesteijn J, Post Uiterweer ED, Derks $\mathrm{JB}$, et al. Placental pathology in early intrauterine growth restriction associated with maternal hypertension. Placenta 2014; 35:696-701.

23. Greer LG, Ziadie MS, Casey BM, Rogers BB, McIntire DD, Leveno KJ. An immunologic basis for placental insufficiency in fetal growth restriction. Am J Perinatol 2012; 29:533-8. 
24. Rozance PJ, Seedorf GJ, Brown A, Roe G, O’Meara MC, Gien J, et al. Intrauterine growth restriction decreases pulmonary alveolar and vessel growth and causes pulmonary artery endothelial cell dysfunction in vitro in fetal sheep. AJP Lung Cell Mol Physiol 2011; 301: L860-71.

25. Kingdom J, Huppertz B, Seaward G, Kaufmann P. Development of the placental villous tree and its consequences for fetal growth. Eur J Obstet Gynecol Reprod Biol 2000; 92: 35-43.

26. Wareing M, Myers JE, O'Hara M, Baker PN. Sildenafil citrate (Viagra) enhances vasodilatation in fetal growth restriction. J Clin Endocrinol Metab 2005; 90:25505.

27. Polglase GR, Barbuto J, Allison BJ, Yawno T, Sutherland AE, Malhotra A, et al. Effects of antenatal melatonin therapy on lung structure in growth-restricted newborn lambs. J Appl Physiol 2017 Aug 17: jap.00783.2016. doi: 10.1152/japplphysiol.00783.2016.

28. Hung MW, Yeung HM, Lau CF, Poon AMS, Tipoe GL, Fung ML. Melatonin Attenuates Pulmonary Hypertension in Chronically Hypoxic Rats. Int. J. Mol. Sci. 2017, 18, 1125; doi: 10.3390/ijms18061125.

29. Gluck L, Kulovich MV. Lecithin/sphingomyelin ratios in amniotic fluid in normal and abnormal pregnancy. Am J Obstet Gynecol 1973; 115:539-46.

30. Procianoy RS, Garcia-Prats JA, Adams JM, Silvers A, Rudolph AJ. Hyaline membrane disease and intraventricular haemorrhage in small for gestational age infants. Arch Dis Child 1980; 55:502-5.

31. Bose C, Van Marter LJ, Laughon M, O'Shea TM, Allred EN, Karna P, et. al. for the Extremely Low Gestational Age Newborn Study Investigators. Fetal growth restriction and chronic lung disease among infants born before the 28th week of gestation. Pediatrics 2009; 124:e450-8.

32. Lal MK, Manktelow BN, Draper ES, Field DJ. Chronic lung disease of prematurity and intrauterine growth retardation: a population-based study. Pediatrics 2003; 111:483-7.

33. Abman SH. Bronchopulmonary dysplasia: "a vascular hypothesis". Am J Resp Crit Care Med. 2001; 164: 1755-6.

34. Sehgal A, Gwini SM, Menahem S, Allison BJ, Miller S, Polglase GR. Preterm growth restriction and bronchopulmonary dysplasia: the vascular hypothesis and 
related physiology. J Physiol. 2018 May 10. doi: 10.1113/JP276040. [Epub ahead of print].

35. Thebaud B \& Abman SH. Bronchopulmonary dysplasia: where have all the vessels gone? Roles of angiogenic growth factors in chronic lung disease. Am J Respir Crit Care Med 2007; 175, 978-985.

36. 11. Janér J, Andersson S, Haglund C, Karikoski R, Lassus P. Placental growth factor and vascular endothelial growth factor receptor-2 in human lung development. Pediatrics 2007; 122, 340-346. 
2

3

4

5

6

7

8

9

\section{Table 1. Histopathology features of maternal and fetal vascular malperfusion*}

\begin{tabular}{|c|c|}
\hline Placental pathology & Comment \\
\hline Maternal vascular malperfusion & $\begin{array}{l}\text { - Placental infarcts } \\
\text { Distal villous hypoplasia- paucity of villi in relation to the } \\
\text { surrounding stem villi. The villi are thin and relatively } \\
\text { elongated-appearing, and syncytial knots are increased. } \\
\text { - Accelerated villous maturation- presence of small or short } \\
\text { hypermature villi for gestational period, usually } \\
\text { accompanied by an increase in syncytial knots. } \\
\text { Decidual arteriopathy- includes acute atherosis, fibrinoid } \\
\text { necrosis with or without foam cells, mural hypertrophy, } \\
\text { chronic perivasculitis, and absence of spiral artery } \\
\text { remodelling, arterial thrombosis and persistence of } \\
\text { intramural endovascular trophoblast in the third trimester. }\end{array}$ \\
\hline Fetal vascular malperfusion (FVM) & $\begin{array}{l}\text { Consistent findings include thrombosis, segmental } \\
\text { avascular villi, and villous stromal vascular karyorrhexis. } \\
\text { Other possible markers, are vascular intramural fibrin } \\
\text { deposition, stem vessel obliteration/fibromuscular } \\
\text { sclerosis, and vascular ectasia. } \\
\text { Segmental-thrombotic occlusion of chorionic or stem villous } \\
\text { vessels, or stem vessel obliteration. } \\
\text { Global-partially obstructed umbilical blood flow with venous } \\
\text { ectasia, intramural fibrin deposition in large vessels, and/or small } \\
\text { foci (<5 villi per focus) of avascular or karyorrhectic villi. The } \\
\text { obstruction is partial or intermittent, but the lesions can be } \\
\text { distributed over much of the placenta. } \\
\text { High-grade FVM is manifest by the finding of }>1 \text { focus of }\end{array}$ \\
\hline
\end{tabular}




\begin{tabular}{|c|c|c|c|}
\hline Characteristics & FGR $n=20$ & AGA $n=20$ & $\mathrm{p}$ \\
\hline Gestational age (weeks) & $29.8 \pm 1.3$ & $30 \pm 0.9$ & 0.78 \\
\hline Birthweight (g) & $923 \pm 168$ & $1403 \pm 237$ & $<0.001$ \\
\hline Pre-eclampsia, n (\%) & $13(65)$ & $12(60)$ & 0.6 \\
\hline Antenatal steroids, $\mathrm{n}(\%)$ & $19(95)$ & $20(100)$ & 0.9 \\
\hline Systolic blood pressure $(\mathrm{mm} \mathrm{Hg})$ & $51 \pm 3$ & $46 \pm 3$ & $<0.001$ \\
\hline Diastolic blood pressure (mm Hg) & $30 \pm 2$ & $27 \pm 3$ & 0.0002 \\
\hline Duration of respiratory support (days) & $37(14,52)^{\wedge}$ & $8(5,21)^{\wedge}$ & 0.01 \\
\hline Bronchopulmonary dysplasia, n (\%) & $8(40)$ & $1(5)$ & 0.019 \\
\hline Maternal vascular malperfusion, $\mathrm{n}(\%)$ & $13(65)$ & $4(20)$ & 0.004 \\
\hline Accelerate villous maturation, $\mathrm{n}(\%)$ & $13(65)$ & $7(35)$ & 0.02 \\
\hline Distal villous hypoplasia, $\mathrm{n}(\%)$ & $3(15)$ & $1(5)$ & 0.3 \\
\hline Chorangioma, $\mathrm{n}(\%)$ & $2(10)$ & $1(5)$ & 0.5 \\
\hline Chronic intervillositis, $\mathrm{n}(\%)$ & $2(5)$ & $1(5)$ & 0.5 \\
\hline Fetal vascular malperfusion, $\mathrm{n}(\%)$ & $5(25)$ & $0(0)$ & 0.02 \\
\hline
\end{tabular}

FGR-fetal growth restriction, AGA-appropriate for gestational age, ${ }^{\wedge}$ median (interquartile) 


\section{Figure legend}

Figure 1a. Maternal vascular perfusion: Placental infarct, $\mathrm{H}$ and $\mathrm{E}$, original magnification Figure 1b. Fetal vascular malperfusion: villous stromal-vascular karyorrhexis (old term hemorrhagic endovasculitis), $\mathrm{H}$ and $\mathrm{E}$, original magnification $\mathrm{x} 100$ Figure 1c. Chronic intervillositis, $\mathrm{H}$ and $\mathrm{E}$, original magnification $\mathrm{x} 400$ Figure 1d. Microscopic chorangioma, $\mathrm{H}$ and E, original magnification x50 

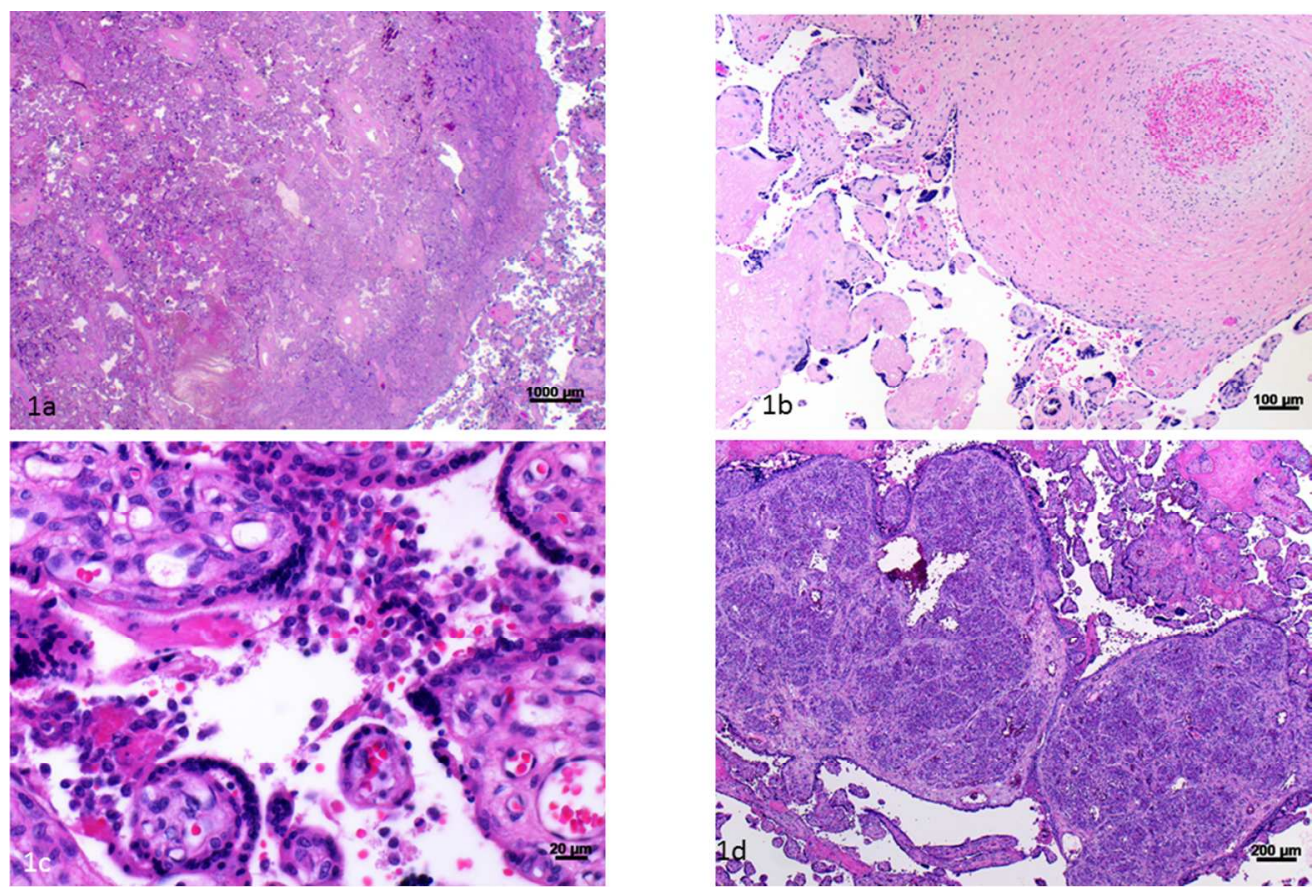

Figure 1a. Maternal vascular perfusion: Placental infarct, $\mathrm{H}$ and $\mathrm{E}$, original magnification Figure 1b. Fetal vascular malperfusion: villous stromal-vascular karyorrhexis (old term hemorrhagic endovasculitis), $\mathrm{H}$ and $\mathrm{E}$, original magnification $\times 100$

Figure 1c. Chronic intervillositis, $\mathrm{H}$ and $\mathrm{E}$, original magnification $\times 400$ Figure 1d. Microscopic chorangioma, $\mathrm{H}$ and $\mathrm{E}$, original magnification $\times 50$ 


\begin{abstract}
Aims: Approximately 6-9\% pregnancies are affected by fetal growth restriction (FGR). Placental alterations related to utero-placental insufficiency in fetal growth restriction (FGR) may induce placental vascular remodeling to the detriment of the fetus. The objective of this study was to study histopathological features of placentae in a cohort of preterm growth restricted infants in comparison to a cohort of preterm appropriately grown infants.
\end{abstract}

Methods: In a cohort of 40 preterm infants' 28-32 weeks' gestation, placental histopathology was evaluated by a histopathologist, masked to the identity of the grouping. Twenty infants had FGR while 20 were appropriate for gestational age (AGA). Predefined histopathological characteristics were assessed based on the Amsterdam Placental Workshop Group Consensus Statement.

Results: The GA and birthweight of the FGR and AGA cohorts were $29.8 \pm 1.3$ vs $30 \pm 0.9$ weeks, $\mathrm{p}=0.78$ and $923 \pm 168$ vs $1403 \pm 237 \mathrm{~g},<0.001$, respectively. Maternal vascular malperfusion, accelerated villous maturation and fetal vascular malperfusion were features which were significantly more common in FGR placentae.

Conclusions: Based on the results of the present study, specific placental histopathological changes may be present in FGR placentae which may reflect the effects of utero-placental insufficiency.

Key words: fetal growth restriction; histopathology; preterm; placenta; vascular malperfusion 


\section{What this paper adds}

- Identifies key placental histopathological characteristics in very preterm infants with FGR

- Studies placental pathology focussed on maternal/fetal malperfusion indices

- Classifies placental pathology according to the most recent consensus statement 


\section{Introduction}

Fetal growth restriction (FGR) affects about 6-9\% pregnancies worldwide, and a combination of prematurity and FGR increases the perinatal mortality or morbidity by 10-20 fold, compared to appropriately-grown preterm infants (1). It is the second highest cause of perinatal death and the commonest cause of stillbirth in the infant $(2,3)$. Fetal programming remains a well-established concept in epidemiological medicine with implications for fetal, pediatric and adult diseases. Abnormalities of the placenta, with reduced feto-placental blood flow accompanying utero-placental insufficiency (UPI), are a major cause of FGR (4-6).

Previous data noted that in early FGR, the placental pathology is characterized by features of hypoxia and reperfusion damage caused by vascular remodelling and/or obstruction of spiral arteries $(7,8)$. Recent information also noted that pregnancies complicated by maternal vascular malperfusion had a 4.5 times higher risk of developing preeclampsia or delivering a FGR infant compared with those without this pathology (9). Importantly, in low-risk pregnancies, maternal vascular malperfusion accounts for approximately $25 \%$ of adverse pregnancy outcomes (such as FGR in the infant or preeclampsia) (9). Common adaptive mechanisms with advancing gestation in healthy pregnancies include a drop in placental vascular resistance and the establishment of a high flow circuit to optimise nutrient and oxygen delivery. This is achieved through vascular adaptations such as angiogenesis and vasodilatation $(4,10)$. In severe cases of FGR, these adaptive mechanism fail resulting in a persistently high placental vascular resistance.

Information from placental histopathology and biomarkers is key to a better understanding of perinatal disease pathophysiology. The physiologic consequences of the altered placental architecture may underlie persistent cardiovascular alterations noted in the newborn and pediatric age groups. This includes a lower elastin content in the extracellular matrix of fetal conductance arteries (due to feto-maternal blood flow abnormalities); elastin is the key determinant of elastic properties (11-15). Recent studies in preterm FGR lambs and human infants noted increased arterial stiffness in the early neonatal period $(16,17)$ which persist into childhood (18). Early identification may identify premature infants at high risk for long term cardiovascular compromise, and allow early intervention and/or increased monitoring.

The objectives of this study were to identify key placental histopathological characteristics in very preterm infants with FGR, compared to an appropriate for gestational 
age (AGA) cohort, with emphasis on maternal/fetal malperfusion indices. In this preliminary study, we hypothesize that in infants with FGR, the effects of UPI may be reflected in placental histopathological changes.

\section{Methods}

The study was approved by the Institution Health Research Ethics Board and informed parental consent was obtained. Twenty very preterm infants (28 to 32 completed weeks of gestation) with birthweight $<10^{\text {th }}$ percentile were compared with 20 preterm AGA infants of the same GA range. GA was determined by fetal dating ultrasound (19). Our selected GA range reflects the majority of moderate to severe early-onset FGR cases. Infants with possible asphyxia (5 minute Apgar score $<5$ ), congenital malformations/heart disease or chromosomal abnormalities, or infants of diabetic mothers were excluded. Archived slides for placental histopathology were examined by a single perinatal pathologist, masked to cohort identity and the clinical outcomes. Predefined histopathological characteristics were assessed based on the Amsterdam Placental Workshop Group Consensus Statement (20). At least three sections of the placental plate, two sections of the umbilical cord and a roll of the extraplacental membranes were examined. Features examined reflected maternal/fetal malperfusion (Table 1). The infants were part of an echocardiographic study for which assessments were made in the second week of life. In that setting, non-invasive blood pressure (BP) measurements were obtained using an appropriate-sized cuff on the right arm with the infant in a quiet state and positioned supine (model Intelli Vue MX 800; Philips, Boeblingen, Germany). The average values of 2 readings were recorded. Infants were prospectively followed to ascertain clinical respiratory morbidity.

\section{Statistics}

Continuous variables were compared using student's t-test and categorical variables were compared using Chi-square or Fisher's exact tests. All analyses were performed using Stata software version 13.0. Significance was set at two-tailed $\mathrm{p}<0.05$.

\section{Results}

The GA at birth amongst the two groups was comparable, but the birthweight was significantly lower in the FGR infants. Twelve of 20 FGR infants weighed $<3^{\text {rd }}$ centile. Table 
2 summarizes the salient demographic and placental characteristics of the study population. Amongst maternal demographics, cigarette smoking during pregnancy and body mass index data was available for only part of the cohort. Amongst FGR group, cigarette smoking was prevalent in 4 (of 17 mothers) compared to 1 (of 12 mothers) in the AGA cohort. Mean body

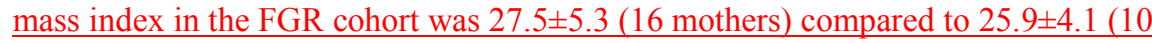
mothers). Blood pressure was significantly higher in FGR infants; no infant was on inotropic support before or at the time of assessment. There were two sets of twins in each cohort; all dichorionic diamniotic. The number of FGR infants with placental changes secondary to maternal vascular malperfusion (such as placental infarcts, distal villous hypoplasia, accelerated villous maturation and decidual arteriopathy, placental ischemia, Figure 1a) and changes secondary to segmental fetal vascular malperfusion (such as fetal vessel thrombosis, avascular villi and stem vessel obliteration, Figure 1b) was significantly greater than AGA controls (Table 2). The placentas of three FGR infants showed chronic intervillositis (Figure 1c) and another three contained microscopic chorangiomas (Figure 1d) (Table 2). The fetoplacental weight ratio was 3.88 \pm 2.3 and $4.9 \pm 1.2$ in FGR and AGA infants respectively, $\mathrm{p}=0.08$. The total duration of respiratory support and the number of infants with bronchopulmonary dysplasia was significantly higher in the FGR cohort. Four FGR infants (no AGA infant) were discharged with home oxygen.

\section{Discussion}

In this cohort of preterm infants we noted significant differences in placental histopathology in the FGR infants compared to AGA infants. Features of maternal and fetal malperfusion were significantly more common in the FGR infants. FGR infants had significantly higher blood pressure and inferior respiratory outcome profiles. This study thus contributes to our understanding of the pathology of the placenta, the scientific bases of the materno-fetoplacental triad, and the ever expanding clinical significance of the defined lesions.

Recent findings of increase placental vascular resistance in ex-vivo models complement what is seen on histopathology (21). Additionally, the persistence of increased resistance in systemic vessels in the early newborn, pediatric and adolescent age groups, supports the fetal programming theory, and placental pathology provides earliest clues to fetal origin of adult diseases $(17,18)$. Our study utilised the Amsterdam Placental Workshop Group Consensus Statement classification for pre-defined definitions and compared FGR 
placentas with gestation matched AGA placentas. Consistency in definition adds value to the placental examination, especially in those with adverse outcomes such as still birth or FGR.

The classic placental findings in FGR pregnancies may be seen on gross inspection (small size and lower weight) as well as on microscopic histopathology. Previous data has noted histopathology lesions to be related to reduced vascular supply of nutrients and oxygen due to maternal vascular malformation (e.g. infarction, villous hypoplasia and increased syncytial knotting) (22). Other findings include multiple thrombotic occlusions in fetal vessels (20) and chronic intervillositis $(20,23)$. In the sheep model of chronic fetal hypoxia, UPI leads to similar histologic findings of vascular remodelling with small lumens and thick walls (24). We noted significant differences between the two groups for maternal and fetal vascular malperfusion indices which might explain the dynamic impairments. In a recent study of flow dynamics on human term FGR placentas compared with AGA placentas, investigators demonstrated that the former had significantly higher resistance, endothelial dysfunction and reduced flow-mediated vasodilatation. The latter is likely caused by a combination of architectural vessel malformation and alterations in placental capillary angiogenesis (25). While UPI is likely the central event, the pathophysiological processes are multiple. The in-utero disruption in the synthesis and deposition of elastin and its replacement with collagen (100 times greater stiffness than elastin) in fetal life play an important role (11). The other critical mechanism is hypoxia induced oxidative stress. Attempts to improve placental function and fetal/neonatal outcomes by administration of drugs like melatonin and sildenafil (26-28) has guided the search for tangible histopathological markers. These may provide early indications and potentially guide the medical management principles with the ultimate objective of minimizing (or preventing) FGR. Melatonin treatment attenuated the thickness of the arteriolar wall and reduced oxidative and inflammatory markers in chronically hypoxic rats. Our group recently showed that in FGR sheep, umbilicoplacental insufficiency is associated with FGR-produced vascular changes in the white matter and subventricular zone of FGR newborn brains (27). Maternal melatonin prevented disruption of the blood brain barrier by protecting perivascular cells essential for the maintenance of vascular homeostasis and stability. Sildenafil is a vasodilator and its administration during pregnancy has been noted to improve placental blood flow.

Effects of these interventions on the above mentioned histopathological characteristics remains to be studied. While no one histopathology lesion could be considered pathognomonic, such changes are found more frequently in placentas where pregnancy was complicated by FGR. Given utero-placental insufficiency is the main underlying factor of 

FGR placentas. The inadequate trophoblastic invasion and the persistence of smooth muscle in the vessel walls may result in changes like atherosis or fibrinoid necrosis of vessels. Such architectural changes in placental vessel walls combined with endothelial dysregulation in FGR is possibly an important cause of placental flow dysregulation. Close histopathology examination of placentae in pregnancies which are complicated by FGR using standard classification and terminology will facilitate further large scale studies.

Our data noted a significantly higher incidence of BPD in the FGR cohort, compared to the GA and gender matched AGA infants. Information about respiratory morbidity from the early 70 s and 80 s suggested otherwise. Gluck et. al. suggested that the abnormalities of pregnancy, including maternal, fetal, and placental conditions, influence the maturation of the fetal lung (29). Certain conditions such as maternal hypertension may accelerate lecithin $\underline{\text { sphingomyelin ratio maturation. Procianoy et al. studied } 19 \text { small for GA infants' } \leq 32 \text { weeks }}$ GA and compared with an equal number of AGA infants. The incidences of hyaline membrane disease (HMD) was noted to be significantly less in the small for GA cohort (74\% vs 5\%) (30). The authors postulated that a stressful environment in utero may enhance maturation and prevent HMD.

$\underline{\text { Recent data however, has focussed on chronic lung disease (CLD) as a more tangible }}$ outcome (rather than HMD), and overwhelmingly supports the role of FGR in its pathophysiology. A recent study in infants born less than 28 weeks GA noted that at 27 weeks GA, 25\% of infants born without FGR developed CLD compared to $60 \%$ of infants with moderate FGR $\left(<10^{\text {th }}\right.$ centile for birthweight $)$ and $90 \%$ with severe FGR $\left(<33^{\text {rd }}\right.$ centile $)$ (31). Importantly, FGR was the only maternal or antenatal characteristic that was highly predictive of CLD. In an observational study on infants $<32$ weeks GA, FGR infants had a significantly higher risk of developing CLD (odds ratio: $1.87,95 \%$ confidence interval [CI]: 1.4-2.5) (32). While CLD pathophysiology is multifactorial, investigators have proposed a $\underline{\text { role for vascular changes as contributory to CLD pathophysiology }(33,34) \text {. A recent }}$ prospective study on preterm FGR infants (28-32 weeks GA) noted significantly thicker and stiffer pulmonary arterial vasculature compared to GA, gender and age matched AGA control infants as well as a significantly higher prevalence of CLD in the FGR cohort (34). This human data and other experimental data, indicates impaired vasculogenesis as a contributory factor in the higher prevalence of CLD in preterm FGR infants $(35,36)$. Persistent effects of FGR on lung structure and function (affecting both alveolar parenchymal and vascular

Formatted: Superscript

Formatted: Superscript 
1

2

3

4

5

6

7

8

Strengths of our study include comparison of FGR with an AGA cohort and the assessment of placental histopathology by an expert perinatal pathologist, masked to the outcomes and grouping of the cohort. The evaluations were done using standard classifications and terminology. Whether placental architectural changes contribute to postnatal respiratory pathology by way of influencing angiogenesis needs prospective analysis. The findings are limited by being a single centre study and small numbers. Maternal demographic data was not available for the complete cohort. In summary, histopathological changes indicative of maternal and fetal malperfusion are significantly more likely in the placentas of preterm FGR infants. Whether placental findings could be the earliest pointers towards the effects of UPI on the placental vascular extracellular matrix, remains to be studied. This assumes significance, given the vascular remodelling, increased stiffness and reduced compliance persist in the neonatal and pediatric age groups.

\section{Acknowledgements}

Supported by an ANZ Trustees/Equity Trustees Medical Research \& Technology in Victoria Grant, a National Health and Medical Research Council and National Heart Foundation of Australia Fellowship, an Australian Research Council Future Fellowship, a Rebecca L. Cooper Medical Research Foundation Fellowship and the Victorian Government's Operational Infrastructure Support Program.

Conflicts of interest: Authors declare no conflicts of interest 


\section{References}

1. Rosenberg A. The IUGR newborn. Semin Perinatol. 2008; 32:219-24.

2. Yanney M \& Marlow N. Paediatric consequences of fetal growth restriction. Semin Fetal Neonatal Med 2004; 9: 411-418.

3. Figueroa-Diesel H, Hernandez-Andrade E, Acosta-Rojas R, Cabero L, Gratacos E. Doppler changes in the main fetal brain arteries at different stages of hemodynamic adaptation in severe intrauterine growth restriction. Ultrasound Obstet Gynecol 2007; 30: 297-302.

4. Chaddha V, Viero S, Huppertz B, Kingdom J. Developmental biology of the placenta and the origins of placental insufficiency. Semin Fetal Neonatal Med 2004; 9: 357-369.

5. Sibley CP, Turner MA, Cetin I, Ayuk P, Boyd CA, D'Souza SW, et al. Placental phenotypes of intrauterine growth. Pediatr Res 2005; 58: 827-832.

6. Kiserud T, Kessler J, Ebbing C, Rasmussen S. Ductus venosus shunting in growth-restricted fetuses and the effect of umbilical circulatory compromise. Ultrasound Obstet Gynecol 2006; 28: 143-149.

7. Brosens I, Pijnenborg R, Vercruysse L, Romero R. The "Great Obstetrical Syndromes" are associated with disorders of deep placentation. Am J Obstet Gynecol 2011; 204:193e201.

8. Kovo M, Schreiber L, Bar J. Placental vascular pathology as a mechanism of disease in pregnancy complications. Thromb Res 2013; 131: S18e21.

9. Wright, E, Audette MC, Ye XY, Keating S, Hoffman B, Lye SJ et al. Maternal Vascular Malperfusion and Adverse Perinatal Outcomes in Low-Risk Nulliparous Women. Obstet Gynecol. 2017; 130: 1112-1120. 
10. Sala C, Campise M, Ambroso G, Motta T, Zanchetti A, Morganti A. Atrial natriuretic peptide and hemodynamic changes during normal human pregnancy. Hypertension 1995; 25: 631-636.

11. Martyn CN, Greenwald SE. Impaired synthesis of elastin in walls of aorta and large conduit arteries during early development as an initiating event in pathogenesis of systemic hypertension. Lancet 1997; 350:953-55.

12. Cheung YF, Taylor MJ, Fisk NM, Tsoi NS. Fetal origins of reduced arterial distensibility in the donor twin in twin-twin transfusion syndrome. Lancet 2000; 355:1157-58.

13. Dobrin PB. Mechanical properties of arteries. Physiol Rev 1978; 58:397-460.

14. Lurbe E, Torro MI, Carvajal E, Alvarez V, Redón J. Birth weight impacts on wave reflections in children and adolescents. Hypertension 2003; 41:646-50.

15. Fouron JC, Teyssier G, Shalaby L, Lessard M, van Doesburg NH. Fetal central blood flow alterations in human fetuses with umbilical artery reverse diastolic flow. Am J Perinatol 1993; 10: 197-207.

16. Polglase GR, Allison BJ, Coia E, Li A, Jenkin G, Malhotra A, et al. Altered cardiovascular function at birth in growth-restricted preterm lambs. Pediatr Res. 2016; 80:538-46.

17. Sehgal A, Allison BJ, Gwini SM, Menahem S, Miller SL, Polglase GR. Vascular ageing and cardiac maladaptation in growth restricted preterm infants. J Perinatol; 2018; 38:92-97.

18. Crispi F, Figueras F, Cruz-Lemini M, Bartrons J, Bijnens B, Gratacos E. Cardiovascular programming in children born small for gestational age and relationship with prenatal signs of severity. Am J Obstet Gynecol 2012; 207:121.e1-9.

19. Fenton TR, Kim JH. A systematic review and meta-analysis to revise the Fenton growth chart for preterm infants. BMC Pediatr. 2013; 13: 59.

20. Khong TY, Mooney EE, Ariel I, Balmus NC, Boyd TK, Brundler MA, et al. Sampling and Definitions of Placental Lesions Amsterdam Placental Workshop Group Consensus Statement. Arch Pathol Lab Med. 2016; 140:698-713.

21. Jones S, Bischof H, Lang I, Desoye G, Greenwood SL, Johnstone ED, et al. Dysregulated flow-mediated vasodilatation in the human placenta in fetal growth restriction. J Physiol. 2015; 593:3077-92. 
22. Veerbeek JH, Nikkels PG, Torrance HL, Gravesteijn J, Post Uiterweer ED, Derks $\mathrm{JB}$, et al. Placental pathology in early intrauterine growth restriction associated with maternal hypertension. Placenta 2014; 35:696-701.

23. Greer LG, Ziadie MS, Casey BM, Rogers BB, McIntire DD, Leveno KJ. An immunologic basis for placental insufficiency in fetal growth restriction. Am J Perinatol 2012; 29:533-8.

24. Rozance PJ, Seedorf GJ, Brown A, Roe G, O’Meara MC, Gien J, et al. Intrauterine growth restriction decreases pulmonary alveolar and vessel growth and causes pulmonary artery endothelial cell dysfunction in vitro in fetal sheep. AJP Lung Cell Mol Physiol 2011; 301: L860-71.

25. Kingdom J, Huppertz B, Seaward G, Kaufmann P. Development of the placental villous tree and its consequences for fetal growth. Eur J Obstet Gynecol Reprod Biol 2000; 92: 35-43.

26. Wareing M, Myers JE, O’Hara M, Baker PN. Sildenafil citrate (Viagra) enhances * vasodilatation in fetal growth restriction. J Clin Endocrinol Metab 2005; 90:25505 .

27. Polglase GR, Barbuto J, Allison BJ, Yawno T, Sutherland AE, Malhotra A, et al. Effects of antenatal melatonin therapy on lung structure in growth-restricted newborn lambs. J Appl Physiol 2017 Aug 17: jap.00783.2016. doi: 10.1152/japplphysiol.00783.2016.

28. Hung MW, Yeung HM, Lau CF, Poon AMS, Tipoe GL, Fung ML. Melatonin Attenuates Pulmonary Hypertension in Chronically Hypoxic Rats. Int. J. Mol. Sci. 2017, 18, 1125; doi:10.3390/ijms18061125.

29. Gluck L, Kulovich MV. Lecithin/sphingomyelin ratios in amniotic fluid in normal and abnormal pregnancy. Am J Obstet Gynecol 1973; 115:539-46.

30. Procianoy RS, Garcia-Prats JA, Adams JM, Silvers A, Rudolph AJ. Hyaline membrane disease and intraventricular haemorrhage in small for gestational age infants. Arch Dis Child 1980; 55:502-5.

31. Bose C, Van Marter LJ, Laughon M, O'Shea TM, Allred EN, Karna P, et. al. for the Extremely Low Gestational Age Newborn Study Investigators. Fetal growth restriction and chronic lung disease among infants born before the 28th week of gestation. Pediatrics 2009; 124:e450-8. 
32. Lal MK, Manktelow BN, Draper ES, Field DJ. Chronic lung disease of prematurity and intrauterine growth retardation: a population-based study. Pediatrics 2003; 111:483-7.

33. Abman SH. Bronchopulmonary dysplasia: "a vascular hypothesis". Am J Resp Crit Care Med. 2001; 164: 1755-6.

34. Sehgal A, Gwini SM, Menahem S, Allison BJ, Miller S, Polglase GR. Preterm growth restriction and bronchopulmonary dysplasia: the vascular hypothesis and related physiology. J Physiol. 2018 May 10. doi: 10.1113/JP276040. [Epub ahead of print].

35. Thebaud B \& Abman SH. Bronchopulmonary dysplasia: where have all the vessels gone? Roles of angiogenic growth factors in chronic lung disease. Am J Respir Crit Care Med 2007; 175, 978-985.

28.36. 11. Janér J, Andersson S, Haglund C, Karikoski R, Lassus P. Placental growth factor and vascular endothelial growth factor receptor-2 in human lung development. Pediatrics 2007; 122, 340-346.

Formatted: Font: $12 \mathrm{pt}$

Formatted: Space After: 0 pt, Line spacing: 1.5 lines 
Table 2. Clinical and placental characteristics of the cohort

3 sections examined or an average of 15 villi per section) with or

without thrombus, or 2 or more occlusive or non-occlusive

thrombi in chorionic plate or major stem villi, or multiple nonocclusive thrombi.

*Amsterdam Placental Workshop Group Consensus Statement 


\begin{tabular}{|c|c|c|c|}
\hline Characteristics & FGR $n=20$ & AGA $n=20$ & $\mathrm{p}$ \\
\hline Gestational age (weeks) & $29.8 \pm 1.3$ & $30 \pm 0.9$ & 0.78 \\
\hline Birthweight (g) & $923 \pm 168$ & $1403 \pm 237$ & $<0.001$ \\
\hline Pre-eclampsia, n (\%) & $13(65)$ & $12(60)$ & 0.6 \\
\hline Antenatal steroids, $\mathrm{n}(\%)$ & $19(95)$ & $20(100)$ & 0.9 \\
\hline Systolic blood pressure $(\mathrm{mm} \mathrm{Hg})$ & $51 \pm 3$ & $46 \pm 3$ & $<0.001$ \\
\hline Diastolic blood pressure ( $\mathrm{mm} \mathrm{Hg})$ & $30 \pm 2$ & $27 \pm 3$ & 0.0002 \\
\hline Duration of respiratory support (days) & $37(14,52)^{\wedge}$ & $8(5,21)^{\wedge}$ & 0.01 \\
\hline Bronchopulmonary dysplasia, n (\%) & $8(40)$ & $1(5)$ & 0.019 \\
\hline Maternal vascular malperfusion, $\mathrm{n}(\%)$ & $13(65)$ & $4(20)$ & 0.004 \\
\hline Accelerate villous maturation, n (\%) & $13(65)$ & $7(35)$ & 0.02 \\
\hline Distal villous hypoplasia, n (\%) & $3(15)$ & $1(5)$ & 0.3 \\
\hline Chorangioma, n (\%) & $2(10)$ & $1(5)$ & 0.5 \\
\hline Chronic intervillositis, $\mathrm{n}(\%)$ & $2(5)$ & $1(5)$ & 0.5 \\
\hline Fetal vascular malperfusion, $\mathrm{n}(\%)$ & $5(25)$ & $0(0)$ & 0.02 \\
\hline
\end{tabular}

Figure legend 
Figure 1a. Maternal vascular perfusion: Placental infarct, $\mathrm{H}$ and E, original magnification Figure 1b. Fetal vascular malperfusion: villous stromal-vascular karyorrhexis (old term hemorrhagic endovasculitis), $\mathrm{H}$ and $\mathrm{E}$, original magnification $\mathrm{x} 100$

Figure 1c. Chronic intervillositis, $\mathrm{H}$ and E, original magnification $\mathrm{x} 400$

Figure 1d. Microscopic chorangioma, $\mathrm{H}$ and E, original magnification x50 